\title{
Aberrant DNA methylation associated with silencing BNIP3 gene expression in haematopoietic tumours
}

\author{
M Murai', M Toyota*,1,2,3, A Satoh', H Suzuki ${ }^{1,2}$, K Akino ${ }^{1,2}$, H Mita ${ }^{2}$, Y Sasaki ${ }^{2}$, T Ishida', L Shen ${ }^{4}$, \\ G Garcia-Manero ${ }^{4}$, J-PJ Issa ${ }^{4}, Y$ Hinoda ${ }^{5}$, T Tokino ${ }^{2}$ and $K$ Imai' $^{1}$
}

'First Department of Internal Medicine, Sapporo Medical University, Sapporo 060-8556, Japan; ²Department of Molecular Biology, Cancer Research Institute, Sapporo Medical University, Sapporo 060-8556, Japan; ${ }^{3}$ PRESTO, JST, Kawaguchi, 332-00 I2, Japan; ${ }^{4}$ Department of Leukemia, MD Anderson Cancer Center, Houston, TX 77030, USA; ${ }^{5}$ Division of Clinical Laboratory, Yamaguchi University School of Medicine, Ube 755-8505, Japan

\begin{abstract}
Hypoxia is a key factor contributing to the progression of human neoplasias and to the development of resistance to chemotherapy. BNIP3 is a proapoptotic member of the Bcl-2 protein family involved in hypoxia-induced cell death. We evaluated the expression and methylation status of BNIP3 gene to better understand the role of epigenetic alteration of its expression in haematopoietic tumours. Methylation of the region around the BNIP3 transcription start site was detected in four acute lymphocytic leukaemia, one multiple myeloma and one Burkitt lymphoma cell lines, and was closely associated with silencing the gene. That expression of BNIP3 was restored by treatment with 5-aza2'-deoxycytidine (5-aza-dC), a methyltransferase inhibitor, which confirmed the gene to be epigenetically inactivated by methylation. Notably, re-expression of BNIP3 using 5-aza2-dC also restored hypoxia-mediated cell death in methylated cell lines. Acetylation of histone $\mathrm{H3}$ in the $5^{\prime}$ region of the gene, which was assessed using chromatin immunoprecipitation assays, correlated directly with gene expression and inversely with DNA methylation. Among primary tumours, methylation of BNIP3 was detected in five of 34 (15\%) acute lymphocytic leukaemias, six of 35 (I7\%) acute myelogenous leukaemias and three of 14 (21\%) multiple myelomas. These results suggest that aberrant DNA methylation of the $5^{\prime} \mathrm{CpG}$ island and histone deacetylation play key roles in silencing BNIP3 expression in haematopoietic tumours.
\end{abstract}

British Journal of Cancer (2005) 92, I 165 - I 172. doi: I0.1038/sj.bjc.6602422 www.bjcancer.com

Published online 8 March 2005

(C) 2005 Cancer Research UK

Keywords: DNA methylation, epigenetics, chromatin

As compared to normal tissues, solid tumours are poorly oxygenated and thus contain regions of hypoxia, which provide a physiologically selective pressure for expansion of cells that have acquired antiapoptotic potential (Graeber et al, 1996). Haematopoietic tumours growing in bone marrow are also in a hypoxic environment, and several lines of evidence suggest that, like solid tumours, they are dependent on vascular support (Aguayo et al, 1999). Indeed, angiogenesis is an important determinant of tumour cell survival under hypoxic conditions, and expression of VEGF is known to be upregulated in acute and chronic myelogenous leukaemia (Aguayo et al, 1999; Mayerhofer et al, 2002). Little is known, however, about how haematopoietic tumour cells escape apoptosis normally induced by hypoxic stress.

First identified via its interaction with adenovirus E1B $19-\mathrm{kDa}$ and $\mathrm{Bcl}-2, \mathrm{BNIP} 3$ is one of the Bcl-2 homology 3 (BH3)-only subfamily of $\mathrm{Bcl}-2$ proteins, which display proapoptotic activity (Boyd et al, 1994). Forced expression of BNIP3 induces cell death characterised by localisation of the protein at the mitochondria, opening of the permeability transition pore, loss of membrane

*Correspondence: Dr M Toyota, First Department of Internal Medicine, Sapporo Medical University, South I,West 16, Chuo-ku, Sapporo 0608543, Japan; E-mail: mtoyota@sapmed.ac.jp

Received 25 July 2004; revised 14 December 2004; accepted 7 January 2005; published online 8 March 2005 potential and production of reactive oxygen species (Regula et al, 2002; Vande Velde et al, 2000). This form of cell death is independent of cytochrome $c$ release from mitochondria and caspase activation (Vande Velde et al, 2000). Expression of BNIP3, which is dramatically increased in response to hypoxia, is regulated in part by hypoxia-inducible factor-1 (HIF-1), a heterodimeric transcription factor comprised of an oxygenregulated $\alpha$ subunit (HIF- $1 \alpha$ ) and a stale nuclear factor (HIF-1 $\beta$ / ARNT), and known to be a mediator of the hypoxic response (Semenza, 1999). Under normoxic conditions, HIF- $1 \alpha$ is rapidly degraded by proteasome after being targeted for ubiquitination (Maxwell et al, 1999). Under hypoxic conditions, degradation of HIF- $1 \alpha$ is suppressed, and expression of BNIP3 is induced.

There is now compelling evidence that in many human neoplasias, epigenetic alteration plays a key role in silencing genes involved in cell cycle regulation, apoptosis, metastasis and immune responses (Jones and Laird, 1999; Toyota and Issa, 1999; Baylin et al, 2001). For example, DNA methylation and histone deacetylation are known to be responsible for silencing various genes in neoplasias (Bird and Wolffe, 1999; Magdinier and Wolffe, 2001; Nguyen et al, 2001). However, although changes in DNA methylation are known to play a role in leukaemogenesis (Melki and Clark, 2002), little is known about epigenetic alteration of genes involved in hypoxia. To clarify the molecular mechanism of the resistance to hypoxia-induced apoptosis in haematopoietic tumours, we examined BNIP3 expression in a panel of 
haematopoietic tumour cell lines and evaluated the DNA methylation and histone acetylation status of the $5^{\prime} \mathrm{CpG}$ island of the BNIP3 gene. Our results indicate that aberrant methylation and histone deacetylation of the region around the transcription start site is closely associated with the loss of BNIP3 expression, and that methyltransferase inhibitors restore expression. The use of such drugs may thus represent an effective new approach to the treatment of haematopoietic tumours.

\section{MATERIALS AND METHODS}

\section{Cell lines and specimens}

We used 14 acute lymphocytic leukaemia (ALL) cell lines (BALL1, Jurkat, CCRF-CEM, CCRF-SB, CCRF-HSB2, Molt4, SupT1, PEER, TALL1, Molt3, TOM1, LB804ALL, NALM21 and NAGL1), four multiple myeloma cell lines (KMS12-PE, RPMI8226, HS-Sultan and KHM1B), two Burkitt lymphoma cell lines (Daudi and Raji) and one myeloid leukaemia cell line (K562). All these cells were cultured in appropriate medium. In addition, we analysed 34 primary ALL, 35 primary acute myeloid leukaemia (AML) and 14 primary multiple myeloma specimens, as described previously (Toyota et al, 2001; Shen et al, 2003).

DNA was extracted from cells and tissue samples using the phenol/chloroform extraction method; total RNA was extracted using ISOGEN (Nippon Gene, Japan) according to the manufacturer's instructions. To analyse restoration of BNIP3 expression, SupT1, PEER, TALL1, Raji and KHM1B cells were incubated for $72 \mathrm{~h}$ with $1 \mu \mathrm{M}$ 5-aza-2'-deoxycytidine (5-aza-dC) (SIGMA, St Louis, MO, USA). SupT1 cells were treated with $0.2 \mu \mathrm{M} 5$-aza-dC, $300 \mathrm{~nm}$ trichostatin A (TSA) or both.

\section{Reverse transcription (RT) - PCR}

Total RNA $(5 \mu \mathrm{g})$ was reverse-transcribed using Superscript III (Invitrogen, Carlsbad, CA, USA) to prepare first-strand cDNA. The primer sequences and PCR parameters used are shown in Table 1. Controls consisted of RNA treated identically but without the addition of reverse transcriptase and are labelled as RT - . The integrity of the cDNA was confirmed by amplifying GAPDH as described previously (Suzuki et al, 2000). Samples $(10 \mu \mathrm{l})$ of amplified product were then subjected to $2.5 \%$ agarose gel electrophoresis and stained with ethidium bromide.

Real-time PCR was carried out using an ABI Prism 7000 (Applied Biosystems, Foster City, CA). Accumulation of PCR product was measured in real time as an increase in SYBR green fluorescence and analysed using ABI Prism 7000 SDS Software (Applied Biosystems). Standard curves relating initial template copy number to fluorescence and amplification cycle were generated using the amplified PCR product as a template, and were then used to calculate the mRNA copy number in each sample. The ratios of the intensities of the BNIP3 and GAPDH signals were considered to be a relative measure of the BNIP3 mRNA level in each specimen.

\section{Western blot analysis}

Cells were lysed in ice-cold Tris buffer (20 mM Tris, $\mathrm{pH} 7.5$ ). containing $137 \mathrm{~mm} \mathrm{NaCl}, 2 \mathrm{~mm}$ EDTA, $1 \%$ Triton X, 10\% glycerol, $50 \mathrm{~mm} \mathrm{NaF}, 1 \mathrm{~mm}$ DTT and a protease inhibitor cocktail (Roche Applied Science, Mannheim, Germany). Samples $(20 \mu \mathrm{g})$ of the cell lysate were then subjected to $10 \%$ SDS-PAGE, after which the resolved proteins were transferred to Immobilon-P membranes (Millipore, Bedford, MA). After blocking with 5\% nonfat milk and $0.1 \%$ Tween-20 in Tris-buffered saline, the membranes were probed with anti-HIF- $1 \alpha$ (Cell Signaling, Beverly, MA, USA) and anti-BNIP3 mouse monoclonal antibodies (Abcam, Cambridge, $\mathrm{UK}$ ). The blots were then visualised using enhanced chemiluminescence (Amersham, Bucks, UK).

\section{Bisulphite treatment}

For bisulphite-PCR, genomic DNA was initially treated with sodium bisulphite (SIGMA) as described previously (Clark et al, 1994). DNA ( $2 \mu \mathrm{g})$ was denatured for $10 \mathrm{~min}$ in $2 \mathrm{M} \mathrm{NaOH}$ at $37^{\circ} \mathrm{C}$ before addition of $30 \mu \mathrm{l}$ of $10 \mathrm{~mm}$ hydroquinone (SIGMA) and $520 \mu \mathrm{l}$ of $3 \mathrm{M}$ sodium bisulphite $(\mathrm{pH} 5.0)$. The mixture was then incubated for $16 \mathrm{~h}$ at $50^{\circ} \mathrm{C}$. The resultant modified DNA was purified using a Wizard DNA Purification System (Promega, Madison, WI, USA), after which it was again treated with $\mathrm{NaOH}$ and precipitated. Finally, the DNA precipitate was resuspended in $20 \mu \mathrm{l}$ of water and stored at $-20^{\circ} \mathrm{C}$ until used.

\section{Combined bisulphite restriction analysis}

Combined bisulphite restriction analysis (COBRA), a semiquantitative methylation analysis, was carried out as described previously (Xiong and Laird, 1997). PCR was performed in a 50- $\mu$ l volume containing $1 \times \mathrm{PCR}$ buffer $(67 \mathrm{~mm}$ Tris $-\mathrm{HCl}, \mathrm{pH} 8.8,16.6 \mathrm{~mm}$ $\left(\mathrm{NH}_{4}\right)_{2} \mathrm{SO}_{4}, \quad 6.7 \mathrm{mM} \quad \mathrm{MgCl}_{2}$ and $10 \mathrm{~mm} \quad \beta$-mercaptoethanol), $0.25 \mathrm{~mm}$ dNTP mixture, $0.5 \mu \mathrm{m}$ each primer and $1.0 \mathrm{U}$ of Hot Start Taq polymerase (TaKaRa, Tokyo, Japan). PCR was then carried out using the primer sequences and conditions listed in Table 1. Primers were designed based on the nucleotide sequences obtained from Genbank (AL162274). In total, $20 \mu \mathrm{l}$ of PCR product were digested with $A f a \mathrm{I}(\mathrm{TaKaRa})$ and precipitated with ethanol, after

Table I Primer sequences for BNIP3 analysis

\begin{tabular}{|c|c|c|c|}
\hline & & Annealing ${ }^{\circ} \mathbf{C}$ (cycles) & Size (bp) \\
\hline $\mathrm{RT}-\mathrm{PCR}$ & $\begin{array}{l}\text { F: 5'-CCACCTCGCTCGCAGACACCAC-3' } \\
\text { R: 5'-GAGAGCAGCAGAGATGGAAGGAAAAC-3' }\end{array}$ & $66(3), 64(4), 62(5), 60(23)$ & 317 \\
\hline Real-time PCR & $\begin{array}{l}\text { F: 5'-GGACAGAGTAGTTCCAGAGGCAGTTC-3' } \\
\text { R: 5'-GGTGTGCATTTCCACATCAAACAT-3' }\end{array}$ & $60(40)$ & 90 \\
\hline BNIP3 & $\begin{array}{l}\text { F: 5'-CCGCGCCGCCTCCTCCGCCTCAC-3' } \\
\text { R: 5'-GCTCCGACCTCCGCTTCCCACCGCC-3' }\end{array}$ & $70(35)$ & 159 \\
\hline GAPDH & $\begin{array}{l}\text { F: 5'-TCGGTGCGTGCCCAGTTGAACC-3' } \\
\text { R: 5'-ATGCGGCTGACTGTCGAACAGGAG-3' }\end{array}$ & $62(35)$ & 246 \\
\hline
\end{tabular}

$\mathrm{Y}=\mathrm{C}$ or $\mathrm{T}, \mathrm{R}=\mathrm{A}$ or $\mathrm{G} ; \mathrm{ChIP}=$ Chromatin immunoprecipitation; $\mathrm{GAPHD}=$ glyceraldehydes-3 phosphate dehydrogenase; COBRA = combined bisulphite restriction analysis. 
A

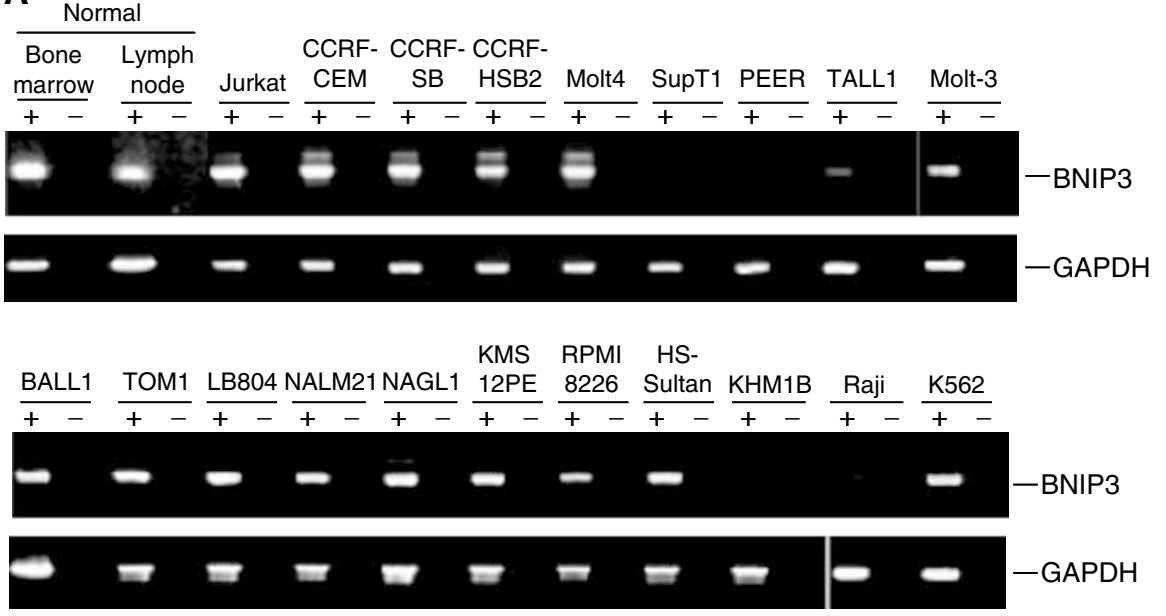

B

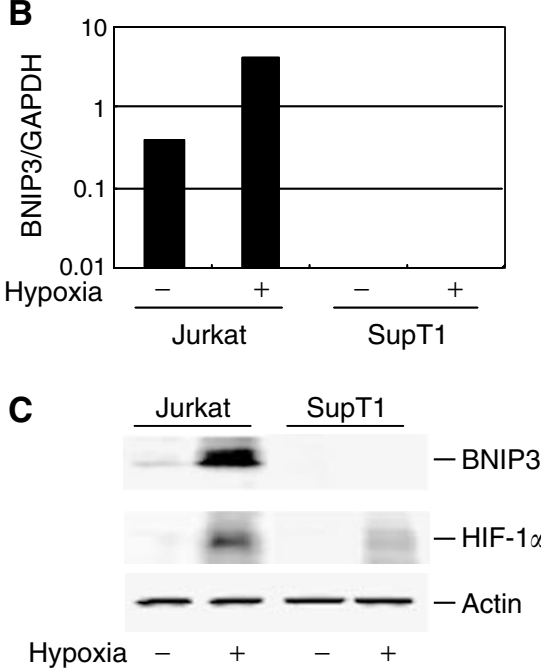

Figure I Expression of BNIP3 in haematopoietic tumour cell lines. (A) A panel of haematopoietic tumours cell lines was analysed for BNIP3 expression by RT-PCR. Glyceraldehyde-3-phosphate dehydrogenase (GAPDH) served as an internal control for the integrity of the cDNA. Corresponding negative controls (amplification without RT) are shown as RT-negative. Cell lines and tissues used are shown on the top. (B) Effect of hypoxia on expression of BNIP3. Real-time PCR was carried out using cDNA from cells subjected to normoxic $\left(20 \% \mathrm{O}_{2}\right.$, hypoxia-) or hypoxic $\left(1 \% \mathrm{O}_{2}\right.$, hypoxia +$)$ conditions for $24 \mathrm{~h}$. Signals normalised to GAPDH are shown on the Y-axis. Cell lines examined are shown below the columns. (C) Western blot analysis of HIF- $\mid \alpha$ and BNIP3. Cells were incubated for $24 \mathrm{~h}$ under normoxic $\left(20 \% \mathrm{O}_{2}\right.$, hypoxia-) or hypoxic $\left(1 \% \mathrm{O}_{2}\right.$, hypoxia +$)$ conditions, after which the proteins were separated by SDS-PAGE, and HIF- $\mid \alpha$, BNIP3 and actin proteins were detected using appropriate antibodies.

which the DNA was subjected to $3 \%$ Nusieve gel electrophoresis and stained with ethidium bromide. The intensity of the methylated alleles was calculated by densitometry using a Lane and Spot Analyzer 6.0 (Atto, Tokyo, Japan).

\section{Bisulphite-sequencing}

For bisulphite-sequencing, the PCR products obtained with Bisulphite-PCR were cloned into pCR4.0 vector using a TOPOTA cloning kit (Invitrogen), after which 10 clones were sequenced for each cell line analysed. The plasmid DNA was then purified using a PI-100 Plasmid Purification System (Kurabo, Tokyo, Japan) and sequenced using a Big Dye Terminator Cycle Sequencing Ready Reaction Kit (Applied Biosystems) with an ABI PRISM 3100 Genetic Analyzer (Applied Biosystems). For direct sequencing, amplified bisulphite-PCR products were electrophoresed in a $1 \%$ Seaplaque gel, excised and purified using a PCR Purification System (Promega). The cycle sequencing reaction was carried out as described above.

\section{Flow cytometry}

Jurkat and TALL1 cells were incubated for $96 \mathrm{~h}$ under normoxic or hypoxic $\left(1 \% \mathrm{O}_{2}, 94 \% \mathrm{~N}_{2}, 5 \% \mathrm{CO}_{2}\right)$ conditions, harvested, fixed with $90 \%$ ethanol and incubated for 30 min with $2 \mathrm{mg} \mathrm{ml}^{-1}$ RNase (SIGMA). In addition, in some instances, TALL1 cells were pretreated for $72 \mathrm{~h}$ with $1 \mu \mathrm{M} 5$-aza-dC. The cellular DNA was then stained with $50 \mathrm{mg} \mathrm{ml}^{-1}$ propidium iodide for $30 \mathrm{~min}$ at $4{ }^{\circ} \mathrm{C}$, after which numbers of stained cells were determined using fluorescent-activated cell sorting (FACS) on a Becton Dickinson FACScaliber.

\section{Chromatin immunoprecipitation analysis}

Chromatin immunoprecipitation (ChIP) analysis was carried out as described previously (Magdinier and Wolffe, 2001). Briefly, DNA was crosslinked with chromatin by incubating cells in $1.0 \%$ formaldehyde for $10 \mathrm{~min}$ at $37^{\circ} \mathrm{C}$. The cells were then washed with ice-cold PBS containing protease inhibitors and resuspended in lysis buffer (1\% SDS, $10 \mathrm{~mm}$ EDTA, $50 \mathrm{~mm}$ Tris- $\mathrm{HCl}, \mathrm{pH} 8.0$ and

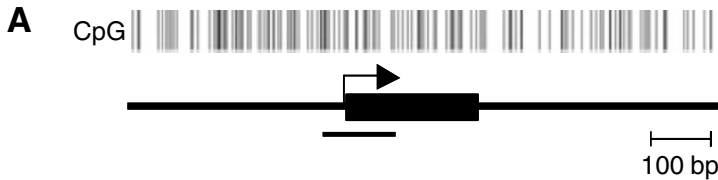

B

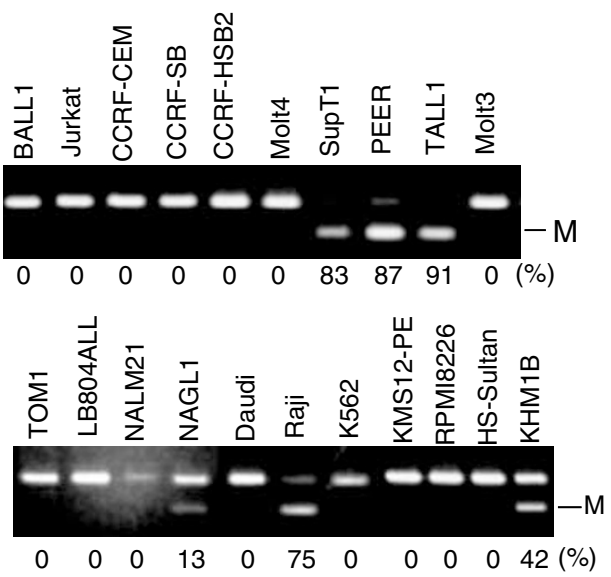

C C SupT1 PEER TALL1 Raji KHM1B

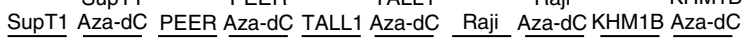

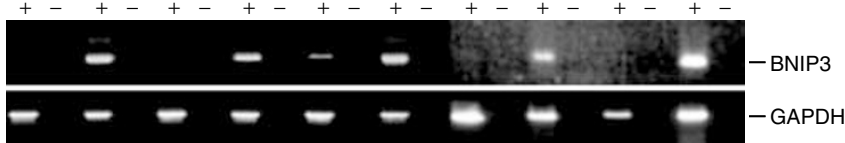

Figure 2 Analysis of BNIP3 methylation in a panel of haematopoietic tumour cell lines. (A) CpG island of BNIP3; CpG sites are shown by vertical bars. The region analysed by COBRA is shown by a solid bar. Exon I is shown by a solid box on a solid line. The transcription start site is shown by an arrow. (B) Aberrant methylation of BNIP3 in haematopoietic tumour cell lines. Methylation of BNIP3 was examined using COBRA. Percentages of methylated alleles are shown below the gels. M: methylated allele. (C) Analysis of BNIP3 expression before and after treatment with 5-aza-dC. Cell lines were treated for $96 \mathrm{~h}$ with $2.0 \mu \mathrm{M} 5$-aza-dC and then harvested, after which RNA was extracted. 


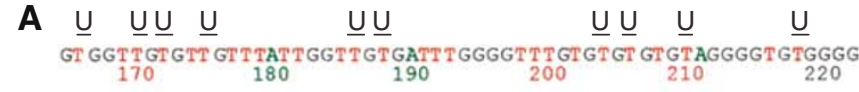

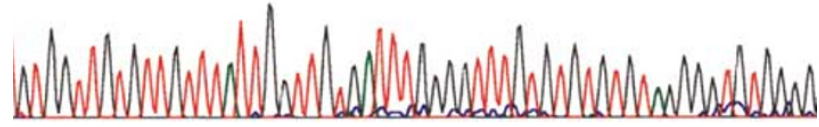
BALL1

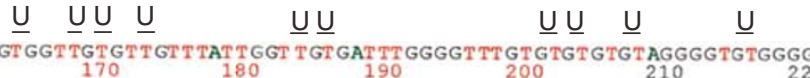

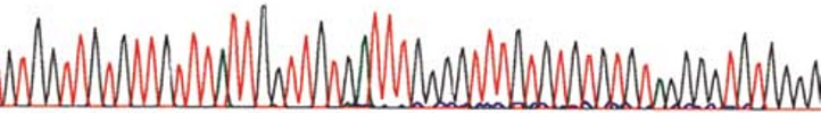
CCRF-CEM

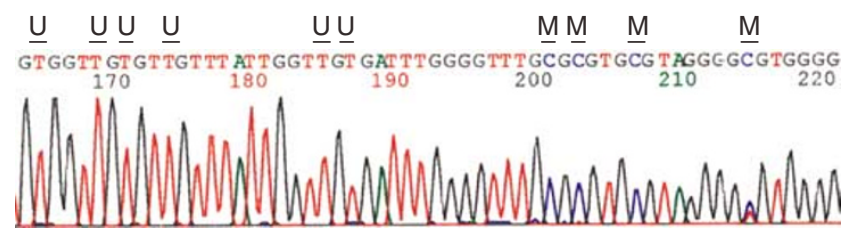

KHM1B

B $+\mathrm{HH}+\mathrm{H}+\mathrm{H}+\mathrm{H}+\mathrm{H} \mathrm{H}+\mathrm{H} \mathrm{HH} \mathrm{HH}+\mathrm{H}+\mathrm{HH}$ 00000000000 ○ 00000 ○ 000 ○00000 00000 $\bigcirc 000000 \bigcirc 000$ ○ 0000000000 ○ 0000000000 ○ $00000 \bigcirc \bigcirc 000$ $000000 \bigcirc \bigcirc 000$ 00000000000 0 00000 00000

100000 00000000000000000000 00000000000100000000000000 00000000000000000000000 000000000000000000000000 \$0000 0000010000000000001 \$0000 00 000 1001000000000010 \$0000000000 00000000000000 00000000000000000000000 000000000000000000000000000 \$0000 00000000000000000000 BALL1

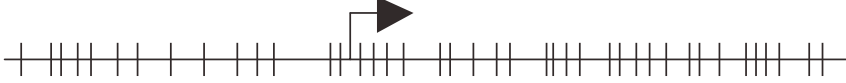

0 $00000000000 \quad 0000000000000000000000000000$

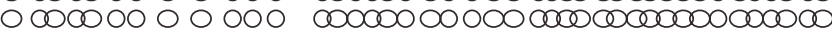
O $0000000000 \quad 00000000000000000000000000$

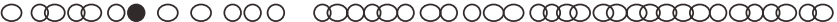

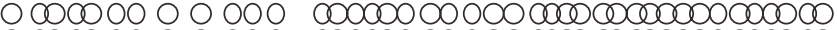

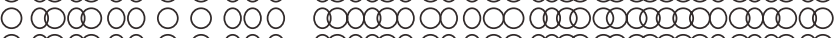
O $00000000000 \quad 0000000000000000000000000$ O DO000 O O $000 \quad 00000000000000000000000$ ○ $00000 \bigcirc \bigcirc 000 \quad 00000000000000000000000000$ ○ $00000 \bigcirc 0000 \quad 0000000000000000000000000$ CCRF-CEM
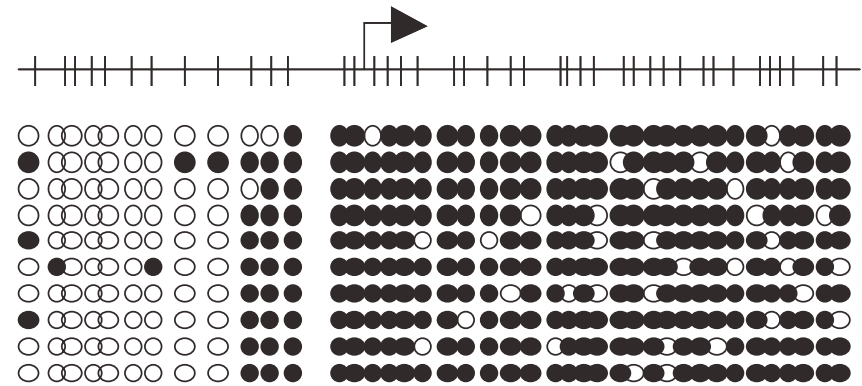

KHM1B

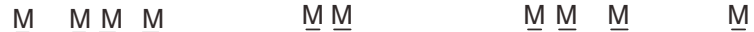

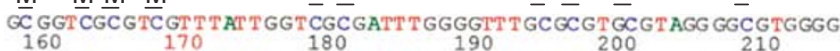

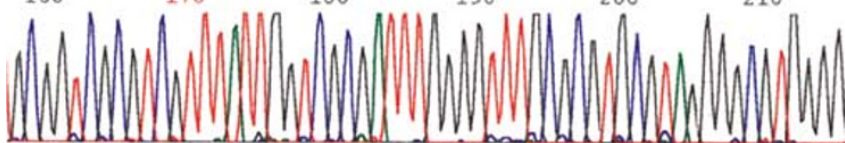

PEER

$M \quad M M \quad M \quad \underline{M} \underline{M} \quad \underline{M} \quad \underline{M} \quad \underline{M}$

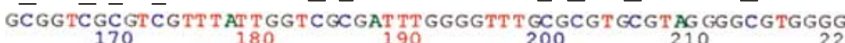

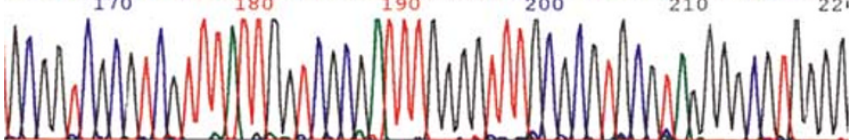

TALL1

$M \quad M M \quad M \quad M M \quad M \quad M \quad M$

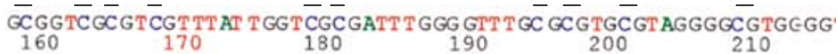

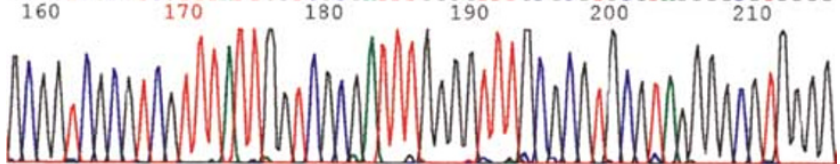
SupT1
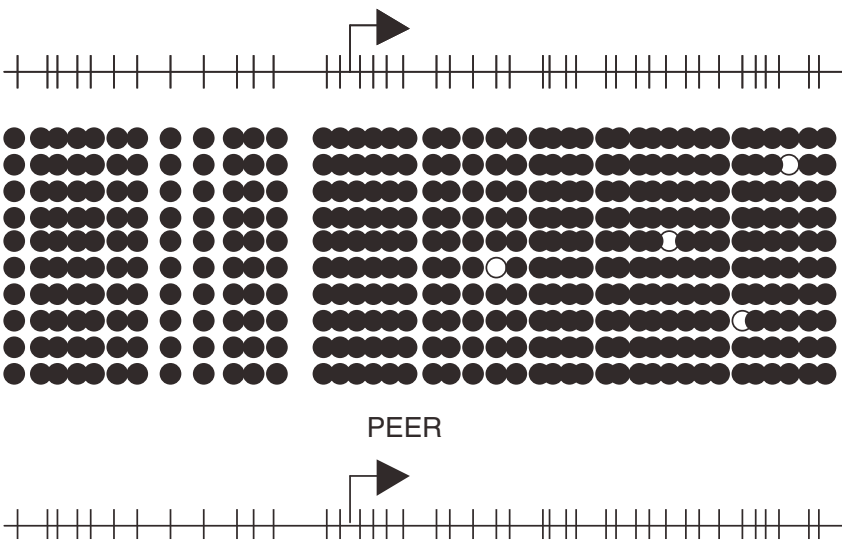

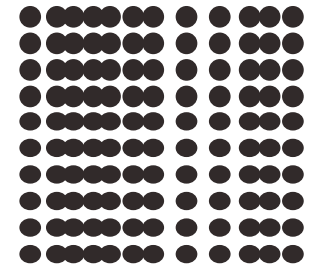

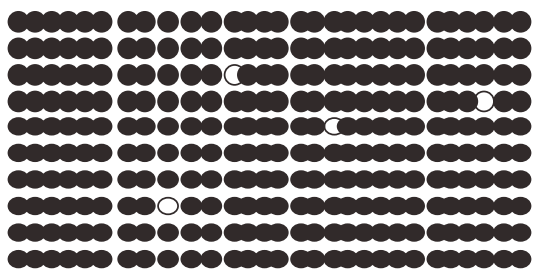

TALL1

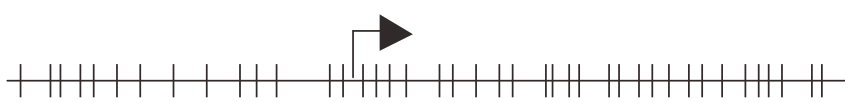

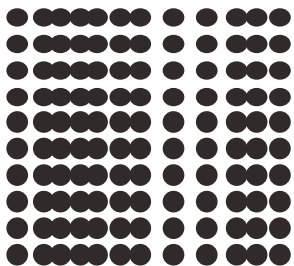

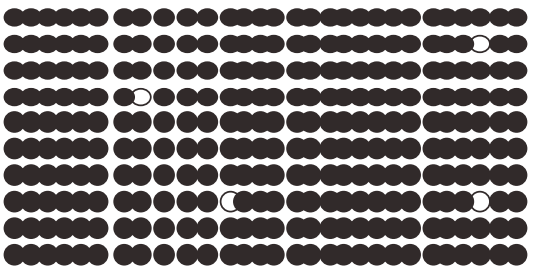

SupT1

Figure 3 Bisulphite-sequencing of BNIP3. (A) Representative results of bisulphite-sequencing. Amplified PCR products were purified from gels and then directly sequenced. The cell lines examined are shown below the column; U, unmethylated CpG sites; M, methylated CpG sites. (B) Summary of bisulphitesequencing. Each circle represents a CpG dinucleotide. Methylation status: open circles, unmethylated; black circles, methylated. At least seven clones were sequenced for each case. The CpG sites in the region analysed are indicated by vertical bar (top). 
protease inhibitor). The DNA within the chromatin was then fragmented into 200-1000-bp segments by sonication, after which immunoprecipitation was carried out for $16 \mathrm{~h}$ at $4{ }^{\circ} \mathrm{C}$ with rotation using antiacetylated histone $\mathrm{H} 3$ antibody (Upstate Biotechnologies, Lake Placid, NY, USA) as a probe. The resultant immune complexes were collected using protein A-agarose, and the DNA was purified by phenol/chloroform extraction, precipitated with ethanol and resuspended in water. About $1 / 100$ of the precipitated DNA was used for PCR. Real-time PCR was carried out using SYBR Green sequence detection reagents (Applied Biosystems) as shown above. The primers used were ChIP-F and ChIP-R; their sequences and the PCR parameters are shown in Table 1. Each experiment was repeated three times, and the average BNIP3/GAPDH signal ratios are shown on the $Y$-axis.

\section{RESULTS}

We initially used RT - PCR to evaluate BNIP3 expression in a panel of 20 haematopoietic tumour cell lines (Figure 1A). Expression of BNIP3 was readily detectable in normal bone marrow and lymph nodes, as well as in 15 of the cell lines tested. Of the remaining five lines, two (TALL1 and Raji) expressed only negligible levels of BNIP3, and three (SupT1, PEER and KHM1B) expressed none at all. The earlier findings that under hypoxic conditions expression of BNIP3 can be induced by the transcription factor HIF- $1 \alpha$ (Bruick, 2000; Guo et al, 2001; Sowter et al, 2001) prompted us to evaluate the extent to which expression of BNIP3 in haematopoietic tumour cell lines could be induced by hypoxia. Using real-time PCR with cDNA prepared from Jurkat and SupT1 cells incubated under hypoxic conditions, we found that hypoxia leads to increased expression of BNIP3 in Jurkat cells but not in SupT1 cells (Figure 1B). When we carried out a Western blot analysis to determine whether the absence of BNIP3 expression in SupT1 cells was caused by impaired HIF- $1 \alpha$ function, we found that hypoxia induced HIF-1 $\alpha$ expression in both Jurkat and Supt 1 cells; thus, the absence of BNIP3 was not caused by a HIF- $1 \alpha$ deficiency (Figure 1C).

Using Blast (http://www.ncbi.nlm.nih.gov/BLAST/) and CpG island Searcher (http://www.uscnorris.com/cpgislands/), we found that the $5^{\prime}$ region of BNIP3 contains a CpG-rich region that satisfies the criteria for a $\mathrm{CpG}$ island ( $\mathrm{CpG}: \mathrm{GpC}=0.65$, $\mathrm{GC} \%=55 \%$; Figure $2 \mathrm{~A}$ ). Then, to explore the role of BNIP3 methylation in haematopoietic tumours, we first used COBRA, a semiquantitative methylation analysis, to examine the methylation status of the region around the transcription start site in a panel of haematopoietic tumour cell lines. Aberrant methylation of BNIP3 was detected in all five cell lines (SupT1, PEER, TALL1, Raji and KHM1B) that either did not express BNIP3 at all or expressed it only to a negligible degree (Figure $2 \mathrm{~B}$ ). By contrast, methylation of BNIP3 was not detected in cell lines that expressed BNIP3, although NAGL1 showed a low level of methylation but expressed BNIP3, nevertheless. Notably, expression of BNIP3 could be restored in the five methylated cell lines by treating them with the methyltransferase inhibitor 5-aza-dC, which strongly suggests that BNIP3 was epigenetically silenced by methylation in these cells (Figure 2C).

To examine the methylation status of each $\mathrm{CpG}$ dinucleotide within the BNIP3 CpG island, bisulphite-sequencing was carried out in six cell lines (BALL1, CCRF-CEM, KHM1B, SupT1, PEER and TALL1). In BALL1 and CCRF-CEM cells, which COBRA showed to be unmethylated, virtually no methylation was detected within the region analysed (Figure 3A, B). Conversely, in SupT1, PEER and TALL1 cells, which COBRA showed to be highly methylated, virtually all of the CpG sites within the region examined were methylated (Figure 3A, B). KHM1B cells showed a more a heterogeneous methylation pattern (Figure 3A, B).
To determine the extent to which the silencing of BNIP3 affected hypoxia-mediated apoptosis, we examined the effect of 5-aza-dC on the incidence hypoxia-mediated cell death among TALL1 cells, which do not otherwise express BNIP3 as a result of the gene's methylation (Figure 4). We found that hypoxia readily induced cell death among control Jurkat cells, which do express BNIP3. Among TALL1 cells, pretreatment with 5 -aza-dC had no significant effect

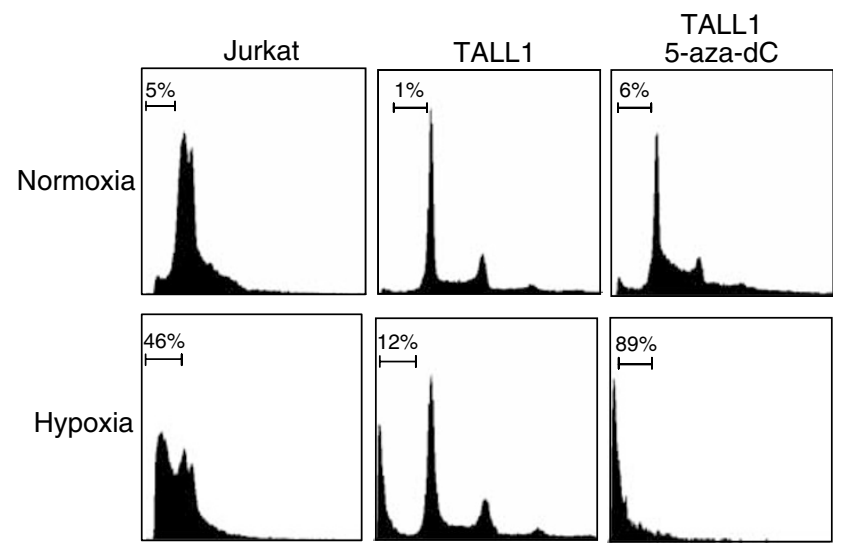

Figure 4 Restoration of hypoxia-mediated apoptosis by treatment with 5-aza-dC. TALLI cells were treated with either mock or I $\mu \mathrm{M} 5$-aza-dC for $72 \mathrm{~h}$ followed by incubation under normoxic or hypoxic conditions for $96 \mathrm{~h}$. Percentages of apoptotic cells were determined by flow cytometry. The unmethylated Jurkat cell line served as a control.

A
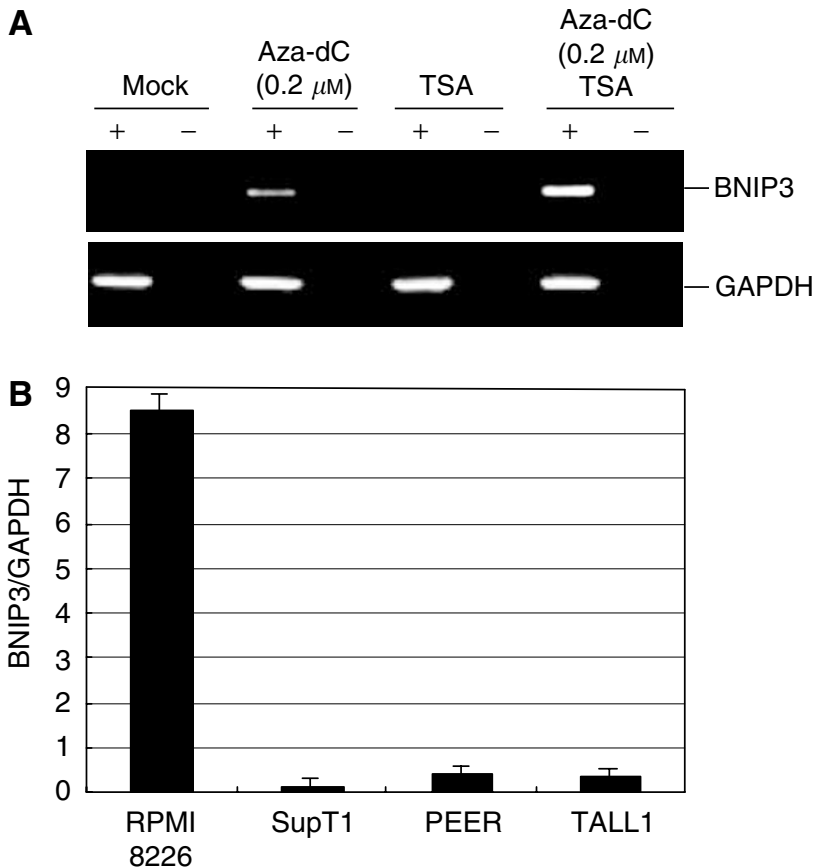

Figure 5 The role of histone deacetylation in silencing BNIP3 gene expression. (A) Effects of DNA methyltransferase and/or histone deacetylase inhibitor on the expression of BNIP3. SupTI cells, which show BNIP3 methylation, were treated with $0.2 \mu \mathrm{M} 5$-aza-dC, $300 \mathrm{nM}$ TSA or both. (B) Histone acetylation examined by ChIP followed by PCR. Chromatin immunoprecipitation analysis was carried out using DNA precipitated with antiacetylated histone $\mathrm{H} 3$ antibody; the bars show the levels of histone acetylation determined by real-time-PCR normalised to the GAPDH signal. The cell lines examined are indicated below. 
on the incidence of cell death under normoxic conditions. Under hypoxic conditions, by contrast, significant numbers of apoptotic cells were detected following pretreatment with 5 -aza-dC, which is indicative of the role played by epigenetic silencing of BNIP3 in protecting cells from hypoxia-mediated apoptosis.

Methylation-dependent gene silencing is reportedly associated with altered chromatin structure involving deacetylation of histone (Jones and Baylin, 2002). Therefore, to assess the role of histone deacetylation in the silencing of BNIP3, we treated the methylated SupT1 cell line with 5-aza-dC and/or TSA, a histone deacetylase inhibitor (Figure $5 \mathrm{~A})$. Treating the cells with a low dose $(0.2 \mu \mathrm{M})$ of 5 -aza-dC induced only a small amount of BNIP3 expression. However, addition of TSA $(300 \mathrm{nM})$ to the 5 -aza-dC had a synergistic effect that markedly increased gene expression, indicating a role for histone deacetylation in silencing of BNIP3 gene expression. We then examined the acetylation status of the BNIP3 CpG island in more detail using ChIP assays with antihistone $\mathrm{H} 3$ antibody and found that acetylation of histone $\mathrm{H} 3$ in the region around the transcription start site correlated directly with gene expression and inversely with DNA methylation (Figure 5B).

Finally, we determined the extent to which BNIP3 is methylated in primary tumours by examining the methylation status of BNIP3 in a panel of primary leukaemia specimens. Using COBRA, methylation of BNIP3 was detected in five of 34 (15\%) ALL specimens, in six of $35(17 \%)$ AML specimens and in three of 14 (21\%) multiple myeloma specimens (Figure 6A). These findings were then confirmed by bisulphite-sequencing of the amplified PCR products. All of the cases found to be methylated using
COBRA were found to be methylated at all of the CpG sites examined (Figure 6B, C).

\section{DISCUSSION}

Tumour cells have an ability to escape apoptosis induced by stresses such as DNA damage, growth factor withdrawal and hypoxia. Resistance to hypoxia-induced apoptosis, in particular, is an important factor in the progression of human neoplasias and in the development of resistance to chemotherapy (Harris, 2002). This is because selective elimination of apoptosis-sensitive cells leads to expansion of cells that are more resistant to treatment and thus contribute to tumour relapse (Schmaltz et al, 1998). In contrast to solid tumours, little is known about how the cells of haematopoietic tumours escape apoptosis induced by hypoxic stress. In the current study, however, we have shown for the first time that aberrant methylation of BNIP3 and histone deacetylation are involved in silencing the gene in a subset of ALLs, AMLs and multiple myelomas. This suggests that tumour cells that do not express BNIP3 have a growth advantage related to their ability to escape apoptosis induced by hypoxia.

BNIP3 was originally identified using a yeast two-hybrid screen for proteins that bind to the adenoviral E1B 19-kDa protein (Boyd et al, 1994). The protein contains a BH3 domain that induces apoptosis (Yasuda et al, 1998) and a C-terminal transmembrane domain that is required for both its mitochondrial localisation and its proapoptotic activity (Chen et al, 1997, 1999; Yasuda et al, 1998); it has been suggested that BNIP3 mediates a necrosis-like cell death by causing mitochondrial dysfunction (Harris, 2002).
A
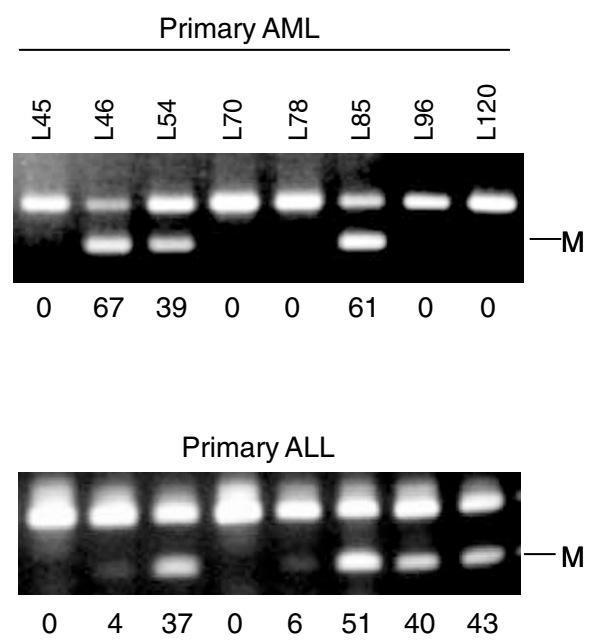

Primary myeloma

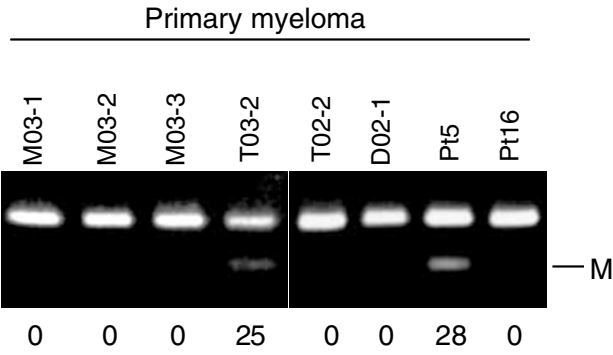

B
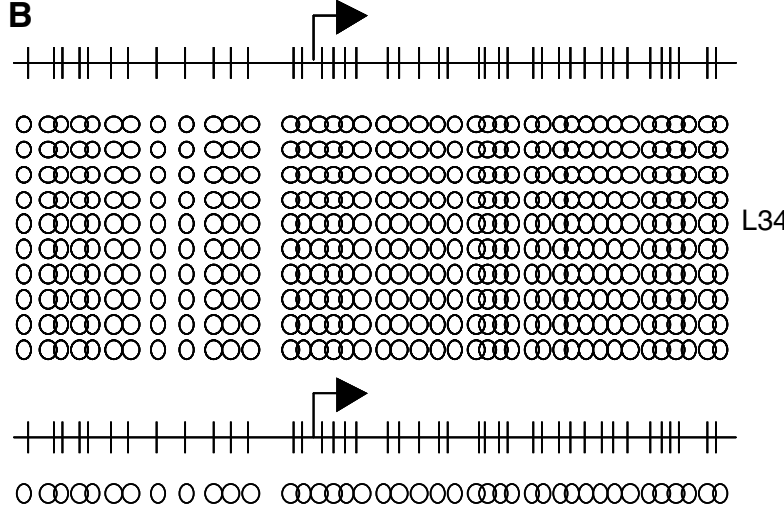
O

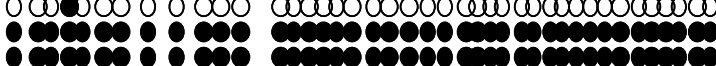

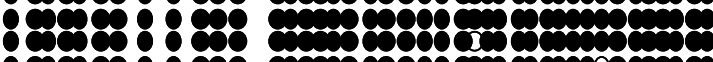
م onn 900 คhल
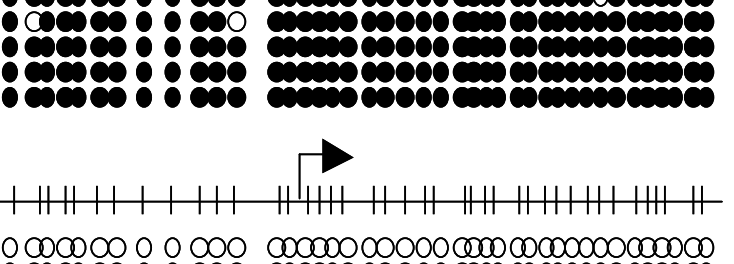

O

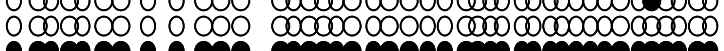

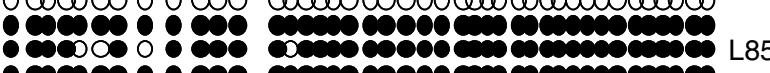

-

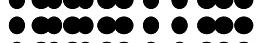

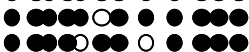
00000 000

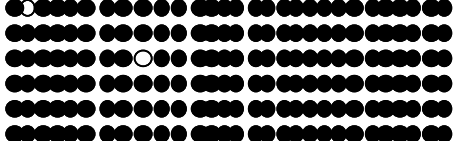

Figure 6 Analysis of BNIP3 methylation in a panel of primary haematopoietic tumours. (A) Methylation of BNIP3 examined using COBRA. Tumour type is shown above the gels. Percentages of methylated alleles were calculated by densitometry and are shown below the gels. (B) Summary of bisulphitesequencing. Each circle represents a CpG dinucleotide. Methylation status: open circles, unmethylated; black circles, methylated. The cases examined are shown on the right. 
Hypoxia induces expression of a group of genes, among which is the transcriptional regulator HIF-1. BNIP3 is a principle target of HIF-1, and the region containing BNIP3's transcription start site also contains HIF-1-binding sequences (Bruick, 2000; Sowter et al, 2001). It is noteworthy that because HIF-1 is involved in both survival and apoptosis of tumour cells, abrogation of the apoptotic pathway caused by silencing BNIP3 may enhance HIF-1-induced survival signals within tumours.

Expression of BNIP3, which is induced by hypoxic stimuli (Guo et al, 2001), has been detected in several human cancer cell lines and cardiac myocytes subjected to hypoxia (Crow, 2002; Kubasiak et al, 2002; Regula et al, 2002). In addition, Sowter et al (2003) recently reported that BNIP3 is highly expressed in the hypoxic regions of high-grade breast cancer. Future clinicopathological analysis may clarify whether there is a specific phenotype for tumours with BNIP3 methylation.

In the present study, we have shown that the silencing of BNIP3 is the result of DNA methylation of its $5^{\prime} \mathrm{CpG}$ island and histone deacetylation. The fact that in methylated cell lines BNIP3 expression was restored by 5 -aza-dC, a methyltransferase inhibitor, confirms that inactivation of the gene was caused by DNA methylation and not by, for example, the loss of transcription factors. DNMT1 and DNMT3b are known to catalyse DNA methylation in cancer cells (Rhee et al, 2002; Toyota et al, 2003); the mechanism by which DNA methylation represses gene expression is not fully understood, however, although histone deacetylation reportedly plays a key role (Bird and Wolffe, 1999;
Cameron et al, 1999; Nguyen et al, 2001). Consistent with that finding, our ChIP assays showed histone $\mathrm{H} 3$ to be deacetylated in cell lines where BNIP3 is silent. It may be that dense methylation of the BNIP3 CpG island attracts methyl-CpG-binding proteins, such as MeCP2 and MBD2, which in turn recruit histone deacetylases (Jones and Baylin, 2002). Recent reports also suggest that histone methylation may be involved in DNA methylation-dependent gene silencing (Fahrner et al, 2002; Nguyen et al, 2002; Kondo and Issa, 2003). Further study will be necessary to clarify the precise mechanism by which CpG methylation silences BNIP3.

In summary, we have shown that DNA methylation and histone deacetylation play key roles in silencing BNIP3 gene expression in haematopoietic tumours. Inhibition of DNA methylation and histone deacetylation act synergistically to induce gene expression, suggesting that BNIP3 may be an effective molecular target for treating a subset of haematopoietic tumours through activation of apoptosis by methyltransferases and histone deacetylase inhibitors.

\section{ACKNOWLEDGEMENTS}

We thank Dr William F Goldman for editing the manuscript. This study was supported in part by Grants-in-Aid for Scientific Research on Priority Areas from the Ministry of Education, Culture, Sports, Science, and Technology (MT, HY, TT, and KI). AS is a research fellow from the Japanese Society for the Promotion of Science.

\section{REFERENCES}

Aguayo A, Estey E, Kantarjian H, Mansouri T, Gidel C, Keating M, Giles F, Estrov Z, Barlogie B, Albitar M (1999) Cellular vascular endothelial growth factor is a predictor of outcome in patients with acute myeloid leukemia. Blood 94: 3717-3721

Baylin SB, Esteller M, Rountree MR, Bachman KE, Schuebel K, Herman JG (2001) Aberrant patterns of DNA methylation, chromatin formation and gene expression in cancer. Hum Mol Genet 10: 687-692

Bird AP, Wolffe AP (1999) Methylation-induced repression - belts, braces, and chromatin. Cell 99: 451-454

Boyd JM, Malstrom S, Subramanian T, Venkatesh LK, Schaeper U, Elangovan B, D'Sa-Eipper C, Chinnadurai G (1994) Adenovirus E1B 19 $\mathrm{kDa}$ and $\mathrm{Bcl}-2$ proteins interact with a common set of cellular proteins. Cell 79: $341-351$

Bruick RK (2000) Expression of the gene encoding the proapoptotic Nip3 protein is induced by hypoxia. Proc Natl Acad Sci USA 97: 9082-9087

Cameron EE, Bachman KE, Myohanen S, Herman JG, Baylin SB (1999) Synergy of demethylation and histone deacetylase inhibition in the reexpression of genes silenced in cancer. Nat Genet 21: 103-107

Chen G, Cizeau J, Vande Velde C, Park JH, Bozek G, Bolton J, Shi L, Dubik D, Greenberg A (1999) Nix and Nip3 form a subfamily of pro-apoptotic mitochondrial proteins. J Biol Chem 274: 7-10

Chen G, Ray R, Dubik D, Shi L, Cizeau J, Bleackley RC, Saxena S, Gietz RD, Greenberg AH (1997) The E1B 19K/Bcl-2-binding protein Nip3 is a dimeric mitochondrial protein that activates apoptosis. J Exp Med 186: $1975-1983$

Clark SJ, Harrison J, Paul CL, Frommer M (1994) High sensitivity mapping of methylated cytosines. Nucleic Acids Res 22: 2990-2997

Crow MT (2002) Hypoxia, BNip3 proteins, and the mitochondrial death pathway in cardiomyocytes. Circ Res 91: 183-185

Fahrner JA, Eguchi S, Herman JG, Baylin SB (2002) Dependence of histone modifications and gene expression on DNA hypermethylation in cancer. Cancer Res 62: 7213-7218

Graeber TG, Osmanian C, Jacks T, Housman DE, Koch CJ, Lowe SW, Giaccia AJ (1996) Hypoxia-mediated selection of cells with diminished apoptotic potential in solid tumours. Nature 379: 88-91

Guo K, Searfoss G, Krolikowski D, Pagnoni M, Franks C, Clark K, Yu KT, Jaye M, Ivashchenko Y (2001) Hypoxia induces the expression of the pro-apoptotic gene BNIP3. Cell Death Differ 8: 367-376

Harris AL (2002) Hypoxia - a key regulatory factor in tumour growth. Nat Rev Cancer 2: $38-47$
Jones PA, Baylin SB (2002) The fundamental role of epigenetic events in cancer. Nat Rev Genet 3: 415-428

Jones PA, Laird PW (1999) Cancer epigenetics comes of age. Nat Genet 21: $163-167$

Kondo Y, Issa JP (2003) Enrichment for histone H3 lysine 9 methylation at Alu repeats in human cells. J Biol Chem 278: 27658-27662

Kubasiak LA, Hernandez OM, Bishopric NH, Webster KA (2002) Hypoxia and acidosis activate cardiac myocyte death through the Bcl-2 family protein BNIP3. Proc Natl Acad Sci USA 99: 1282512830

Magdinier F, Wolffe AP (2001) Selective association of the methyl-CpG binding protein MBD2 with the silent p14/p16 locus in human neoplasia. Proc Natl Acad Sci USA 98: 4990 - 4995

Maxwell PH, Wiesener MS, Chang GW, Clifford SC, Vaux EC, Cockman ME, Wykoff CC, Pugh CW, Maher ER, Ratcliffe PJ (1999) The tumour suppressor protein VHL targets hypoxia-inducible factors for oxygendependent proteolysis. Nature 399: 271-275

Mayerhofer M, Valent P, Sperr WR, Griffin JD, Sillaber C (2002) BCR/ABL induces expression of vascular endothelial growth factor and its transcriptional activator, hypoxia inducible factor-1alpha, through a pathway involving phosphoinositide 3-kinase and the mammalian target of rapamycin. Blood 100: $3767-3775$

Melki JR, Clark SJ (2002) DNA methylation changes in leukaemia. Semin Cancer Biol 12: 347 - 357

Nguyen CT, Gonzales FA, Jones PA (2001) Altered chromatin structure associated with methylation-induced gene silencing in cancer cells: correlation of accessibility, methylation, MeCP2 binding and acetylation. Nucleic Acids Res 29: 4598-4606

Nguyen CT, Weisenberger DJ, Velicescu M, Gonzales FA, Lin JC, Liang G, Jones PA (2002) Histone H3-lysine 9 methylation is associated with aberrant gene silencing in cancer cells and is rapidly reversed by 5-aza-2'-deoxycytidine. Cancer Res 62: 64566461

Regula KM, Ens K, Kirshenbaum LA (2002) Inducible expression of BNIP3 provokes mitochondrial defects and hypoxia-mediated cell death of ventricular myocytes. Circ Res 91: 226-231

Rhee I, Bachman KE, Park BH, Jair KW, Yen RW, Schuebel KE, Cui H, Feinberg AP, Lengauer C, Kinzler KW, Baylin SB, Vogelstein B (2002) DNMT1 and DNMT3b cooperate to silence genes in human cancer cells. Nature 416: $552-556$ 
Schmaltz C, Hardenbergh PH, Wells A, Fisher DE (1998) Regulation of proliferation-survival decisions during tumor cell hypoxia. Mol Cell Biol 18: $2845-2854$

Semenza GL (1999) Regulation of mammalian O2 homeostasis by hypoxiainducible factor 1. Annu Rev Cell Dev Biol 15: 551-578

Shen L, Toyota M, Kondo Y, Obata T, Daniel S, Pierce S, Imai K, Kantarjian HM, Issa JP, Garcia-Manero G (2003) Aberrant DNA methylation of p57KIP2 identifies a cell-cycle regulatory pathway with prognostic impact in adult acute lymphocytic leukemia. Blood 101: 4131-4136

Sowter HM, Ferguson M, Pym C, Watson P, Fox SB, Han C, Harris AL (2003) Expression of the cell death genes BNip3 and NIX in ductal carcinoma in situ of the breast; correlation of BNip3 levels with necrosis and grade. J Pathol 201: 573-580

Sowter HM, Ratcliffe PJ, Watson P, Greenberg AH, Harris AL (2001) HIF-1dependent regulation of hypoxic induction of the cell death factors BNIP3 and NIX in human tumors. Cancer Res 61: 6669-6673

Suzuki H, Itoh F, Toyota M, Kikuchi T, Kakiuchi H, Imai K (2000) Inactivation of the 14-3-3 sigma gene is associated with 5' CpG island hypermethylation in human cancers. Cancer Res 60: 4353-4357
Toyota M, Issa JP (1999) CpG island methylator phenotypes in aging and cancer. Semin Cancer Biol 9: 349-357

Toyota M, Kopecky KJ, Toyota MO, Jair KW, Willman CL, Issa JP (2001) Methylation profiling in acute myeloid leukemia. Blood 97: $2823-2829$

Toyota M, Sasaki Y, Satoh A, Ogi K, Kikuchi T, Suzuki H, Mita H, Tanaka $\mathrm{N}$, Itoh F, Issa JP, Jair KW, Schuebel KE, Imai K, Tokino T (2003) Epigenetic inactivation of CHFR in human tumors. Proc Natl Acad Sci USA 100: $7818-7823$

Vande Velde C, Cizeau J, Dubik D, Alimonti J, Brown T, Israels S, Hakem R, Greenberg AH (2000) BNIP3 and genetic control of necrosis-like cell death through the mitochondrial permeability transition pore. Mol Cell Biol 20: $5454-5468$

Xiong Z, Laird PW (1997) COBRA: a sensitive and quantitative DNA methylation assay. Nucleic Acids Res 25: 2532-2534

Yasuda M, Theodorakis P, Subramanian T, Chinnadurai G (1998) Adenovirus E1B-19K/BCL-2 interacting protein BNIP3 contains a $\mathrm{BH} 3$ domain and a mitochondrial targeting sequence. J Biol Chem 273: $12415-12421$ 